\title{
Deregulation with Consensus *
}

\author{
Sandro Brusco ${ }^{\dagger} \quad$ Hugo Hopenhayn ${ }^{\S}$
}

July 2006 - Revised December 2006.

\begin{abstract}
We analyze the problem of eliminating an inefficient regulation, such as protection, in a dynamic model in which there is incomplete information and unanimous approval from all parties involved is necessary. Existing firms have heterogeneous cost, and efficiency requres some of them to shut down when the inefficient regulation is eliminated. The government can set up a revelation mechanism, giving subsidies and requiring firms to exit the market at a given time depending on the information collected. Under full commitment the optimal policy prescribes that some inefficient firms remain active and are subsidized. The optimal policy takes a simple form, with at most two times at which the firm are allowed to exit.
\end{abstract}

${ }^{*}$ We are very grateful to Matt Mitchell whose comments substantially improved the paper.

${ }^{\dagger}$ Department of Economics, State University of New York at Stony Brook, and Dipartimento di Scienze Economiche, Aziendali e Statistiche, Università Statale di Milano. E-mail: sbrusco@notes.cc.sunysb.edu.

${ }^{\S}$ Department of Economics, University of California at Los Angeles. E-mail: hopen@econ.ucla.edu. 


\section{Introduction}

Many forms of regulation are inefficient so that substantial gains from deregulation are possible. However, the removal of the inefficiency may require the consensus of the groups protected by the regulation. Such groups are often fairly large and heterogeneous, and the relevant information private. Consider the case of eliminating protection in a given market. The rents lost by any given producer depend on its production capabilities; while a marginal producer can choose to exit with little loss, a more productive firm will have more at stake. Likewise, if consumers' valuations of the product are also private, how can the necessary transfers be financed so that no consumer loses with the change?

We analyze the problem of eliminating an inefficient regulation that keeps prices artificially high while obtaining consensus from all agents involved. The planner designs an optimal mechanism to maximize a weighted sum of incumbent firms' profits and consumer surplus. Firms have different cost functions and only the statistical distribution of costs is known to the planner. Agents are infinitely lived and the planner can choose time paths for subsidies. Since the elimination of the inefficient regulation is going to decrease firms' profits, the planner has to make transfers to existing firms in order to obtain their consensus. We consider a mechanism with balanced budget, so that transfers must be financed by taxes on consumers. In order to simplify the discussion in the rest of the paper we will assume that the inefficient regulation to be eliminated is a protectionist tariff, although it should be clear that the results apply in general to all inefficient regulations.

When each firm produces a fixed quantity we show that under quite general conditions the optimal subsidy scheme for the planner is to offer

firms a lump sum transfer at the time the tariff is eliminated and then to offer a subsidy per unit of output to all domestic producers remaining active. The level of the production subsidy is set in such a way that some, but not 
all, inefficient firms (i.e. firms with average cost above the international price) prefer to leave the industry. It is important to note that, although the planner could choose a full menú of pairs exit times-lump sum transfers, under the optimal policy all exit occurs immediately, as soon as the tariff is eliminated. This result is analogous to the problem of a durable goods monopolist who is able to commit to a price policy (see Stokey [14]) ${ }^{1}$. We also establish that a larger weight of firms in the welfare function results in less residual inefficiency: more rather than less deregulation. The intuition is that in that case the planner is more willing to give information rents to the firms exiting the market, and this in turn implies that a larger portion of inefficient firms will leave.

Similar results hold when the firm can vary the quantity produced and have a more general cost function, provided that the planner cannnot monitor the quantity produced by each firm. In this case we show that the mechanism is also quite simple, allowing either for exit only at most two dates.

The optimal policy with commitment does not totally eliminate protection and is thus ex post inefficient. Thus, the classic inconsistency problem pointed out by Kydland and Prescott [8] arises. In fact, the problem has the same structure as the durable good monopolist problem first analyzed by Coase [2]. If governments have only limited commitment, the optimal time consistent solution will imply gradual elimination of subsidies over time. As the length of the commitment period decreases, the speed at which subsidies are lowered increases, and in the limit all subsidies are eliminated immediately. These results follow directly from Gul, Sonnenschein and Wilson [7]. Notice that, in this context, elimination of the subsidies implies that the

\footnotetext{
${ }^{1}$ For that problem, Stokey [14] establishes that the optimal policy is to make all sales as soon as the good is introduced and zero afterwards. In a way, our result generalizes this one to the case where consumers choose not only the timing but also the quantity consumed of a durable good and have different utility functions.
} 
government is unable to discriminate among firms with different productivity. This implies that a larger amount of lump sum transfers has to be paid, reducing the gains to consumers.

The problem of removing inefficient regulations, such as trade barriers, in the presence of political constraints has been analyzed in many papers. For example, Fernandez and Rodrik [6] consider a model where inefficient regulations have to be removed by majority voting. They assume that individuals are uncertain about the gains from regulation and that side transfers are not possible. In such a framework, they show the presence of a 'status quo bias': reforms that are beneficial ex post to a majority of the population are rejected ex ante by individuals who fear to be among the losers rather than among the winners. More recent work, such as Davidson and Matusz [3] and Davidson, Matusz and Nelson [4], has focused on what kind of practical policies can be adopted to promote free trade in the presence of political constraints. Our discussion is of a more theoretical nature, as we explore the nature of the optimal mechanism for deregulation under the constraint of unanimity.

Among the papers that have taken a more theoretical perspective it is worth mentioning Dewatripont and Roland [5] and Mitchell and Moro [9]. Dewatripoint and Roland consider a model where an efficiency-enhancing structural reform can be introduced in an industry at the cost of increasing workers' disutility. Workers are heterogeneous in that they have different degrees of aversion to effort. Side transfers are possible but they have to be financed through distortionary taxation, so that the planner prefers to keep them as low as possible. The structural reform has to be approved by an exogenously specified proportion of workers. For the case of unanimity (which is the one we consider) they show that in a static model either full reform or partial reform ${ }^{2}$ can be chosen depending on the value of the

\footnotetext{
${ }^{2}$ The reform is partial if some inefficient workers are left in the industry.
} 
parameters. In a dynamic two-period model, full reform can be sustained as a perfect Bayesian equilibrium whenever it was sustainable in the static model. On the other hand, a partial reform cannot be sustained as a perfect Bayesian equilibrium due to time consistency problems. In this case only a gradual reform can be sustained: all inefficient workers eventually leave the industry, but the most inefficient ones leave immediately and the others leave only in the second period. Our model is different because we consider a continuous time-infinite horizon model with a continuum of types. In this setting, we show that what Dewatripont and Roland call partial reform is always optimal: The planner always allows some inefficient firms to stay in the industry. Furthermore, the analysis of time consistency is much more complicated, and no easy prediction is available.

Mitchell and Moro [9] analyze a problem similar to ours, in which an inefficient regulation has to be removed and the winners have to compensate the losers. The extent of the loss is unobserved, and the winners set up a revelation mechanism in which the probability of deregulation and the compensation offered to the losers depend on the announcement about the extent of the loss. Their main point is that the optimal mechanism for the winner will typically not allow for elimination of inefficient regulation with probability 1 even when it is common knowledge that the losses are inferior to the gains. The reason is that the information rents that have to be paid to the losers in order to insure unanimity may be large, and the potential winners prefer to reduce those rents distorting the deregulation decision. Thus, the main purpose of their model is to explain why inefficient policies may persist. In constrast our model is dynamic and it is always possible to Pareto improve the current situation. Our focus is instead on the nature of the optimal mechanism.

The rest of the paper is organized as follows. In section 2 we set up the basic framework and show that the optimal solution under commitment is to let some inefficient firms to stay in the industry. Section 3 deals with time 
consistency issues. In section 4 we show that the basic conclusions obtained in section 2 carry on to the case of more general cost functions provided that side trading among domestic firms is allowed. Section 5 contains concluding remarks. All the proofs are collected in the appendix.

\section{The Basic Model}

At date 0 a country is considering whether or not to eliminate protection in a given industry. A tariff is in place that results in zero imports and a local price $p^{0}$ which exceeds the international price $p_{I}$. There is a continuum of consumers with reservation values for a single unit of the good $v_{i} \in[0, \bar{v}]$. The instantaneous utility of each consumer is $v-p$ if the good is bought at

price $p$, and 0 otherwise. The distribution of $v$ is stationary and given by a measure $G$ with a continuous density $g$ on $[0, \bar{v}]$. Demand for the good at each instant can therefore be represented by a downward sloping demand function $D(p)=G(\bar{v})-G(p)$, for $p \leq \bar{v}$.

On the production side, there is a continuum of firms. Each firm $i$ produces a single unit of the good at each instant of time at a cost $c_{i}$. This cost can only be avoided by exiting the industry, a decision assumed to be irreversible. Costs are distributed according to a cdf $F$ with a continuous density $f$ on the interval $\left[0, p^{o}\right]$. Firms and consumers are risk neutral and discount flows at a common rate $r$. The market is competitive, so initially $D\left(p^{0}\right)=F\left(p^{0}\right)$. We make the following regularity assumption.

Assumption 1 The functions $g$ and $f$ satisfy the following properties:

- $\left(v-p_{I}\right) \frac{g(v)}{G(\bar{v})-G(v)}$ is increasing in $v$.

- $\left(c-p_{I}\right) \frac{f(c)}{F\left(p^{o}\right)-F(c)}$ is increasing in $c$.

Total surplus is maximized eliminating the tariff and letting the equilibrium price drop to $p_{I}$. All firms with $\operatorname{costs} c_{i}>p_{I}$ would exit the industry, and 
a permanent flow of imports $D\left(p_{I}\right)-F\left(p_{I}\right)$ would be required. Absent private information, the appropriate transfers from consumers to firms can be arranged so that all agents gain from this deregulation. This cannot be achieved when consumer valuations and firms' costs are private information.

We now proceed to characterize the set of Pareto improving allocations that can be achieved with deregulation under private information. This can be viewed as a standard mechanism design problem, and the revelation principle allows us to restrict attention to direct mechanisms.

A mechanism consists of a list of functions $\{d(t, v), \tau(v), T(c), S(c)\}$, where $d(t, v)$ specifies the probability that a consumer with valuation $v$ consumes the good at date $t ; \tau(v)$ is the present value of net transfers from this type of consumer to the principal; $T(c) \in[0, \infty]$ specifies the time at which a firm with cost $c$ must exit the industry and $S(c)$ corresponds to the present value of net transfers from the principal to this type of firm ${ }^{3}$.

Since we assume full commitment of the principal to the mechanism, the description of the problem can be simplified by eliminating the time subscripts and expressing all relevant units in terms of expected net present values at period zero. Define

$$
D(v)=\int_{0}^{\infty} e^{-r t} d(t, v) d t \quad A(c)=\frac{1-e^{-r T(c)}}{r} .
$$

A consumer of type $v$ announcing $\widetilde{v}$ obtains a utility

$$
\widetilde{U}(v, \widetilde{v})=D(\widetilde{v})\left(v-p_{I}\right)-\tau(\widetilde{v})
$$

and we define $U(v)=\widetilde{U}(v, v)$. Similarly, the expected discounted profit of a producer with cost $c$ announcing $\widetilde{c}$ is

$$
\widetilde{\Pi}(c, \widetilde{c})=S(\widetilde{c})-A(\widetilde{c}) c
$$

\footnotetext{
${ }^{3}$ Notice that we are assuming that a firm produces the goods and delivers them to the government up to time $T(c)$. All payments are included in the transfer $S(c)$. On the other hand, a consumer pays the price $p_{I}$ whenever she buys the good, as well as the tax $\tau(v)$.
} 
with $\Pi(c)=\widetilde{\Pi}(c, c)$. We constrain the principal to a balanced budget from the mechanism. A deficit would require taxing other agents in the population, who would then lose with the reform. The budget constraint of the principal is

$$
\int_{0}^{\bar{v}} \tau(v) g(v) d v+p_{I} \int_{0}^{p^{0}} A(c) f(c) d c \geq \int_{0}^{p^{0}} S(c) f(c) d c .
$$

On the revenue side we have the taxes paid by consumers and the value of the goods delivered by firms. On the expenditure side we have the transfers paid to the firms. The mechanism must be Pareto improving, so that consumers and firms must have utilities and profits at least as high as under the status quo.

An optimal mechanism solves the following problem:

$$
\max _{\{A(c), D(v), S(c), \tau(v)\}} \int_{0}^{\bar{v}} U(v) g(v) d v+\alpha \int_{0}^{p^{0}} \Pi(c) f(c) d c
$$

subject to budget balance, individual rationality and incentive compatibility ${ }^{4}$.

In order to discuss the solution, we present here a simplified version of the problem. It is shown in the appendix that the solution to the simplified problem is also a solution to the general problem. Suppose that the planner is considering the following simple policy:

- Consumer with type $v<v^{*}$ do not buy the good. Consumers with type $v \geq v^{*}$ buy the good paying a price $v^{*}=p_{I}+X$, where $X$ is the excise tax imposed on the good.

- Firms with a cost $c \leq c^{*}$ remain in the industry and receive a subsidy $c^{*}-p_{I}$, all other firms leave the industry. A lump sum transfer equal to $\frac{p^{o}-c^{*}}{r}$ is given to all firms.

This policy is ex ante individually rational for firms and consumers (provided $\left.v^{*} \leq p^{o}\right)$ and incentive compatible. It is also ex post individually rational for

\footnotetext{
${ }^{4} \mathrm{~A}$ full description of the constrained maximization problem is in the appendix.
} 
high cost firms to leave the market and for the low valuation consumers to abstain from consumption, so that the exit and consumption decisions need not be monitored. The values $v^{*}$ and $c^{*}$ are obtained as solution to

$$
\max _{v^{*}, c^{*}} \int_{v^{*}}^{\bar{v}} \frac{\left(v-v^{*}\right)}{r} g(v) d v+\alpha\left\{\int_{0}^{c^{*}} \frac{\left(p^{o}-c\right)}{r} f(c) d c+\frac{\left(p^{o}-c^{*}\right)}{r}\left(1-F\left(c^{*}\right)\right)\right\}
$$

s.t.

$$
\begin{gathered}
\frac{\left(v^{*}-p_{I}\right)}{r}\left[G(\bar{v})-G\left(v^{*}\right)\right] \geq \frac{\left(p^{o}-p_{I}\right)}{r} F\left(c^{*}\right)+\frac{\left(p^{o}-c^{*}\right)}{r}\left(F\left(p^{o}\right)-F\left(c^{*}\right)\right) \\
v^{*} \leq p^{o}
\end{gathered}
$$

where the first constraint is the budget constraint (this is the form taken by (2) under the proposed policy) and the second constraint is the individual rationality constraint for consumers (a price higher than $p^{o}$ would make some consumers worse off). The next proposition establishes that the solution to problem (4) is actually a solution to the more general problem (3).

Proposition 1 Suppose that assumption 1 holds and let $\left(c^{*}, v^{*}\right)$ be a solution to problem (4). Then the following is an optimal policy:

1. At time 0 pay a lump sum $\frac{p^{o}-c^{*}}{r}$, to all firms.

2. At each instant $t \geq 0$ sell the good at price $v^{*}$ and pay a subsidy $c^{*}-p_{I}$ to all firms which do not exit.

Thus, the optimal policy is typically ex post inefficient, since usually $c^{*}>p_{I}$. An interesting question that may be posed in our model is: How does the optimal policy changes when $\alpha$ changes? The level of $c^{*}$ determines the amount of ex post inefficiency; lower values correspond to more efficient policies, with $c^{*}=p_{I}$ corresponding to full productive efficiency. Thus, the issue is what happens to $c^{*}$ as $\alpha$ varies.

For each value $c^{*}$ define $V\left(c^{*}\right)$ as the lowest value of $v^{*}$ that satisfies the budget constraint (5). It is clear that welfare maximization requires 
choosing $V\left(c^{*}\right)$ whenever $c^{*}$ is chosen. Therefore, the objective function can be written as

$$
\begin{aligned}
W\left(c^{*}, \alpha\right)= & \int_{V\left(c^{*}\right)}^{\bar{v}}\left(v-V\left(c^{*}\right)\right) g(v) d v \\
& +\alpha\left[\int_{0}^{c^{*}}\left(c^{*}-c\right) f(c) d c+F\left(p^{0}\right)\left(p^{0}-c^{*}\right)\right]
\end{aligned}
$$

and the optimization problem can be written as:

$$
\max _{c^{*} \in\left[0, p^{o}\right]} W\left(c^{*}, \alpha\right)
$$

The properties of the optimal policy $c^{*}$ depend on the properties of $W\left(c^{*}, \alpha\right)$ with respect to $c^{*}$ and $\alpha$. The following result shows that productive inefficiency decreases as $\alpha$ increases. ${ }^{5}$

Proposition 2 The optimal value $c^{*}$ is non-increasing in $\alpha$.

The intuition for the result is that an increase in $\alpha$ makes it more desirable for the social planner to transfer money to the firms, and higher lump sum transfers to firms are associated to more exit and higher efficiency. In fact, consider the extreme case in which the goal is to maximize profits under IR and IC for consumers (i.e. $\alpha \rightarrow \infty$ ). In this case the optimal policy is to set a tax $X=p^{o}-p_{I}$ and pay a lump sum subsidy $\frac{p^{o}-p_{I}}{r}$ to the firms, and no production subsidy thereafter. This leaves the consumers exactly indifferent between protection and liberalization. Inefficient firms, i.e. firms with $c>p_{I}$, exit the market immediately and are strictly better off than under protection, while efficient firms remain in the market and obtain the same discounted profit as under protection.

\footnotetext{
${ }^{5}$ As pointed out to us by Matt Mitchell, there is still the issue of allocative inefficiency in comparing $v^{*}$ to $p_{I}$. In comments to our paper, Matt Mitchell writes: "In the extreme case where $\alpha$ goes to $\infty$ and $c^{*}$ approaches $p_{I}$, productive efficiency is achieved at the cost of maintaining maximum allocative inefficiency; $v^{*}$ is at the simple monopoly price for a monopolist with access to both the domestic firms and the international price, i.e. has a marginal cost that is the minimum of the supply curve and $p_{I}$. "
} 
In general, under the optimal mechanism described in proposition (1) the firms remaining in the industry have the same value of discounted profits before and after the deregulation, while firms that exit earn an additional profit of $\frac{c-c^{*}}{r}$, which can be considered an incentive rent. Thus, increasing $c^{*}$ decreases the incentive rents that have to be paid to the firms. The reduction of incentive payments benefits consumers, so that the optimal mechanism gives lower incentive payments the higher is the weight on consumers' welfare. Correspondingly, as the weight of firms in the social welfare function increases the planner increases the incentive payment to firms, thus decreasing $c^{*}$.

\section{Time Consistency}

Consider the case $\alpha=0$ where the planner wishes to maximize consumer surplus subject to the other constraints. ${ }^{6}$ The optimal solution calls for keeping in the industry a number of firms which are known to be inefficient (firms with cost $\left.c \in\left(p_{I}, c^{*}\right]\right)$. It is obvious that ex post all the participants would like the planner to change the policy. This in turn destroys the $e x$ ante incentives for firms to reveal truthfully their cost. In this section we discuss what happens when the commitment assumption is removed, so that the time consistency problem first discussed by Kydland and Prescott [8] appears.

The problem of a planner deciding to remove an inefficient regulation with unanimous consensus is formally identical to the problem of a durable good monopolist. To see this, suppose that the government gives a uniform subsidy $\frac{p^{o}-p_{I}}{r}$ to each firm in the industry and let the price paid to each firm drop to $p_{I}$. This makes sure that no firm is worse off, so that the individual rationality constraint is satisfied. After that, the government sells 'rights to

\footnotetext{
${ }^{6}$ For simplicity we restrict our analysis to this extreme case, though we conjecture results carry through more generally.
} 
exit the industry'. A firm leaving the industry at time $t$ has to pay a price $q(t)$. Define the 'utility' of a firm of cost $c$ leaving the industry at time $t$ as:

$U(t, c)=\frac{p^{o}-p_{I}}{r}+\frac{1-e^{-r t}}{r}\left(p_{I}-c\right)-e^{-r t} q(t)=\frac{p^{o}-c}{r}+e^{-r t}\left[\frac{c-p_{I}}{r}-q(t)\right]$

The problem of the firm is now formally identical to the problem of a buyer of a durable good with valuation $\theta=\frac{c-p_{I}}{r}$. The higher the cost, the higher the value that a firm attaches to an exit permit. A firm which never leaves the industry obtains utility $\frac{p^{o}-c}{r}$, thus making sure that it is not worse off with respect to protection.

We can now see that the problem of choosing the profit-maximizing price schedule $q(t)$ under the constraint that each consumer voluntarily chooses the time of purchase is equivalent to the problem of minimizing the subsidy to firms while at the same time making them at least as well off as under protection $^{7}$. Stokey [14] has shown that the solution in this case is to sell the good as soon as it is introduced.

As previously observed, an important feature of the solution is that some inefficient firms survive. The analog in the monopolist problem is that some consumers who are known to value the good more than the marginal cost are left unserved. The reason why this happens is standard. By letting some inefficient firms stay in the industry the planner is forced to pay more subsidies in order to compensate for losses, but at the same time it is able to lessen the incentive compatibility problem. Thus, it is convenient to raise the cut off cost $c^{*}$ as long as the increase in the amount of loss-compensating subsidy is smaller than the savings induced by the reduced incentive rents for firms with a lower cost.

\footnotetext{
${ }^{7}$ In our framework the planner desires to maximize the revenue from the sale of exit permits only if $\alpha=0$. If $\alpha>0$ then the planner will not choose the price schedule that maximizes revenue. However, given the nature of the solution proposed in the previous section it remains true that the optimal policy with commitment is still to set a constant price for the exit permit.
} 
When time consistency problems are taken into account, the nature of the problem changes. Rather than an optimization problem we are now considering a repeated game between the planner (the monopolist) and firms (the consumers). We should therefore investigate what outcomes are sustainable as a perfect Bayesian equilibrium of the game.

Results on the durable goods monopolist literature are of two types. First, we have 'folk theorems' results, establishing that almost everything can be sustained as the outcome of a subgame perfect equilibrium (see Stokey [15] for a continuous time model and Ausubel and Deneckere [1] for a discrete time model.) Second, we have 'Coase conjecture' results, establishing that when we limit attention to a particular class of equilibria then the outcome is close to the one predicted by Coase [2], i.e. the monopolist offers the good immediately at the competitive price. In particular, Stokey [15] proves that in a continuous time model the Coasian outcome is the only one that can be supported as a perfect rational expectations equilibrium if some continuity requirements are imposed on agents' expectation. For the discrete time version Gul, Sonnenschein and Wilson [7] prove that in all equilibria in which consumers adopt stationary strategies the price charged by the monopolist in the first period approaches the competitive price as the discount factor tends to 1 .

These results are easily translated in our model. The results in Stokey [15] imply that in a model where the planner can revise its policy in continuous time any time path of exit can be observed as the outcome of a perfect Bayesian equilibrium. On the other hand, when continuity requirements on firms' expectations are imposed then the only subgame perfect equilibrium outcome is that all inefficient firms (i.e. firms with $c>p_{I}$ ) exit immediately and each firm is given a subsidy $\frac{p^{o}-p_{I}}{r}$.

A 'discrete time' version is obtained if it is assumed that the planner can commit to maintain a given policy for a period of length $\Delta$. This would be the case, for example, if a change of policy requires approval by the Congress 
and the Congress only meets at discrete intervals. Then we have exactly the discrete time model with discount factor $\delta=e^{-r \Delta}$. For this model, the results of Ausubel and Deneckere [1] and Gul, Sonnenschein and Wilson [7] hold: As $\Delta$ approaches zero there are equilibria where the planner gets arbitrarily close to the first best (commitment) solution, but in all stationary equilibria the Coasian outcome is approached.

\section{General Cost Functions and Optimal Mecha- nisms with no Arbitrage}

In this section we drop the special assumptions on technology imposed in the previous sections, allowing for more general cost functions. We maintain however the same assumptions on consumers' preferences. We show that, under some regularity assumptions on the technology used by the firms, it is still possible to obtain a simple optimal policy, namely one that splits the set of firms into two subsets and allows for at most two exit times.

The cost function of a firm is now given by $c(q, s)$. The parameter $s$ indicates the 'efficiency level' of a firm, with an higher $s$ indicating a more efficient firm, so that $c(q, s)$ indicates the cost of producing $q$ for a firm of type $s$. The distribution is $f(s)$ on the support $[\underline{s}, \bar{s}]$, and we have

$\int_{\underline{s}}^{\bar{s}} f(s) d s<+\infty$. For convenience we will set $\int_{\underline{s}}^{\bar{s}} f(s) d s=1$, although the result holds for any finite mass of firms. We denote by $\pi(p, s)$ the profit function (i.e. $\left.\pi(p, s)=\max _{q} p q-c(q, s)\right)$ and by $q(p, s)$ the supply function of a firm of type $s$. Consumers' preferences are the same as before, with instantaneous utility functions given by $v-p$ and valuations distributed according to $g(v)$. The regularity assumptions needed to obtain a simple optimal policy are collected below.

Assumption 2 1. For each $p$ the function $\pi(p, s)$ is bounded in $s$. Let $\bar{\pi}(p)$ be the bound such that $|\pi(p, s)| \leq \bar{\pi}(p)$ for each $s$; 
2. $\frac{\partial q(p, s)}{\partial p}>0$ and $\frac{\partial q(p, s)}{\partial s}>0$ for each $(p, s)$.

3. For each $s \in[\underline{s}, \bar{s})$ and for each $p>p^{0}$ the following inequality is satisfied:

$q(p, \bar{s})-q(p, s) F(s)-\int_{s}^{\bar{s}} q(p, x) f(x) d x<\left(p-p_{I}\right) \int_{s}^{\bar{s}} \frac{\partial q(p, x)}{\partial p} f(x) d x$

Part 1 is satisfied whenever $\lim _{q \rightarrow \infty} \frac{\partial c(q, s)}{\partial q}=\infty$ for each $s$, a very weak assumption. Part 2 is also very weak. It requires that the supply of each firm be increasing in price, and that more efficient firms produce more. Part 3 is the really binding assumption, and its interpretation is not easy. One way to interpret it is that the firms are not 'too different'. In particular, notice that the assumption is automatically satisfied when all firms are identical (i.e., $q(p, s)$ is not a function of $s)$, since in that case the left hand side of the inequality is zero and the right hand side is positive. More in general, the assumption is satisfied when the difference between the supply of the most efficient firm is not much larger than the supply of other firms. From the technical point of view, the assumption is required to make sure that we can limit attention, when looking at individual rationality constraints, to the constraint relative to the most efficient firm only ${ }^{8}$. When part 3 of assumption 2 is satisfied then the behavior of the most efficient firm is not too different from the behavior of less efficient firms. This makes sure that their individual rationality levels (that is, the quantities $\frac{\pi\left(p^{0}, s\right)}{r}$ ) are not too different. The implication is that when all incentive constraints hold with equality and the individual rational constraint is satisfied for type $\bar{s}$, then it will automatically hold for all other types. This allows us to characterize the solution via the standard relaxed problem considered in the literature. The appendix contains an example provided to us by Matt Mitchell, that gives a more intuitive interpretation of this assumption. ${ }^{9}$

${ }^{8}$ Remember that in our problem the IR constraints depend on the type $s$.

${ }^{9}$ Our proof uses the strict inequality of part 2 of the assumption to rule out the possi- 
When firms are not restricted to unit production, a planner can possibly dictate not only whether a firm has to leave the industry or stay but also the exact level of production at each instant. A mechanism is therefore characterized by an array $\{\tau(v), D(v), \tilde{q}(t, s), T(s), \widetilde{S}(s)\}$ where $\tau(v)$ and $D(v)$ are as in section $2, \widetilde{q}(t, s)$ denotes the quantity produced at time $t$ by a firm announcing type $s, T(s)$ is the exit time and $\widetilde{S}(s)$ is the total transfer to a firm announcing $s$.

An important issue not arising in the previous framework is that the planner has to make sure that the quantity $\tilde{q}(t, s)$ is actually produced by the firm. The reason is that the level of output produced may be used as a screening device: In order to keep incentives aligned, it may be important that firms bear the cost of producing the prescribed output. The problem is that if $\tilde{q}(t, s)$ is such that for any two firms the marginal costs are not equal, there will be arbitrage opportunities. Unless explicitly prevented from doing so, firms will engage in side-trading.

We assume that the planner is unable to monitor the trade between firms, that is firms can trade between each other "behind their back" in order to fulfill their output quotas. This is equivalent to put an extra constraint on the problem.

If we allow for side trading among firms, we need to make assumptions about the organization of the market for this good. Given the structure of our model, and in particular the maintained hypothesis that there is a continuum of firms, it is natural to assume that the market is competitive.

Given supply functions $q(p, s)$ and an exit schedule $T$, the equilibrium arbitrage price at a given time $t$, denoted $p(t)$, is given by the unique solution

bility of prices going above $p_{0}$, which seems a fairly anomalous feature. The assumption is not satisfied in the case of constant output considered in the first section or when capacity constraints bind. It can be conjectured (e.g. by continuity) that the same properties derived should hold if the assumption only required weak inequalities. 
to the equation

$$
\int_{\{s \mid T(s)>t\}} q(p(t), s) d F(s)=\int_{\{s \mid T(s)>t\}} \tilde{q}(t, s) d F(s) .
$$

On the right hand side of (6) we have the total quantity that the firm have to produce at time $t$, which is given by the production quota $\tilde{q}(t, s)$ mandated by the government for a firm of type $s$ integrated over the set of firms active at time $t$ (i.e. all firms with an exit time $T(s)>t$ ). On the right hand side we have the total quantity that the firms active at time $t$ are willing to produce at a price $p(t)$, the aggregate supply.

Unless the recommended plan of action is such that $q(p(t), s)=\tilde{q}(t, s)$, arbitrage will take place. It is easy to see that for any mechanism that leads to arbitrage, we can construct an analogous mechanism with no arbitrage by imposing this equality and modifying appropriately the transfers to account for the cash flows that would have taken place in the original mechanism. This motivates the following definition.

Definition 1 A no arbitrage mechanism is a mechanism $\{T, \tilde{q}, \widetilde{S}\}$ such that there exists a price function $p(t)$ with the property that $q(p(t), s)=\tilde{q}(t, s)$ at each time $t$ and for each type $s$.

In a no-arbitrage mechanism the planner, rather than announcing output quotas, can equivalently announce a price schedule $p(t)$ at which she is willing to buy the output produced by firms active at time $t$. Furthermore, as a consequence of report $s$ the planner sets an exit time $T(s)$ and a transfer $S(s)$ to the firm ${ }^{10}$. Taking this into consideration, the mechanism gives a firm of type $s$ announcing $\hat{s}$ a net present value:

$$
\widetilde{\Pi}(\hat{s}, s)=\int_{0}^{T(\hat{s})} e^{-r t} \pi(p(t), s) d t+S(\hat{s})
$$

\footnotetext{
${ }^{10}$ Under this interpretation of the mechanism, the transfer $S(s)$ is in addition to the price paid for delivery of the goods.
} 
An optimal mechanism maximizes social welfare subject to incentive compatibility and individual rationality for all firms and consumers, as well as budget balance. The constraints related to consumers are the same as in the previous section. As for firms, define $\Pi(s)=\widetilde{\Pi}(s, s)$. Then incentive compatibility requires $\Pi(s) \geq \widetilde{\Pi}(\hat{s}, s)$ for each pair $(s, \hat{s})$, and individual rationality requires $\Pi(s) \geq \frac{\pi\left(p^{o}, s\right)}{r}$.

Looking now at the budget constraint, define the total quantity produced by firms active at time $t$ when the price is $p(t)$ as:

$$
Q(p(t), t)=\int_{\{s \mid T(s)>t\}} q(p(t), s) d F(s)
$$

The planner is committed to buy all goods produced by domestic firms at $p(t)$. The goods can be sold at the international price, so that the planner has to pay $\left(p(t)-p_{I}\right) Q(p(t), t)$ at each instant $t$.

The program to be solved by the planner is the following:

$$
\max _{\tau, d, p, T, S} \int_{\underline{v}}^{\bar{v}} U(v) g(v) d v+\alpha \int_{\underline{s}}^{\bar{s}} \Pi(s) f(s) d s
$$

s.t.

$$
\begin{gathered}
\Pi(s) \geq \frac{\pi\left(p^{o}, s\right)}{r}, \quad \Pi(s) \geq \widetilde{\Pi}(\hat{s}, s) \quad \text { for each } s, \hat{s} \\
U(v) \geq \max \left\{\frac{v-p^{o}}{r}, 0\right\}, \quad U^{\prime}(v)=D(v) \\
\int_{\underline{v}}^{\bar{v}} \tau(v) g(v) d v \geq \int_{\underline{s}}^{\bar{s}} S(s) f(s) d s+\int_{0}^{\infty} e^{-r t}\left(p(t)-p_{I}\right) Q(p(t), t) d t
\end{gathered}
$$

Before proceeding, we observe that on the consumers' side the optimal policy must have the same form as in the previous sections, a consequence of the fact that we have not changed the assumptions about consumers' preferences.

Lemma 1 Under the optimal policy, there exists a tax $X$ and a type $v^{*}=$ $p_{I}+X$ such that all types $v \in\left[0, v^{*}\right)$ never buy the good and all types $v \in\left[v^{*}, \bar{v}\right]$ always buy the good at price $p_{I}+X$. 
The lemma implies that we can concentrate the analysis on the elements of the mechanism regarding firms, i.e. the triplet $(p(t), T(s), S(s))$. We can now prove the following result.

Proposition 3 There is a solution to the optimal program with the following characteristics:

1. There are at most two exit times, $T_{1}$ and $T_{2}$, and cut-off types $s_{1}$ and $s_{2}$, such that firms with $s \in\left[\underline{s}, s_{1}\right]$ exit at $T_{1}$ and firms with $s \in\left(s_{1}, s_{2}\right]$ exit at time $T_{2}$.

2. The price paid to firms changes at most at time $T_{1}$ i.e. a price $p_{1}$ is adopted between 0 and $T_{1}$ and a price $p_{2}$ is maintained after $T_{1}$.

3. There are at most two levels of subsidy, $S_{1}$ and $S_{2}, S_{1} \geq S_{2}$. Subsidy $S_{1}$ is paid to firms exiting at time $T_{1}$ and subsidy $S_{2}$ is paid to firms exiting at $T_{2}$.

The formal proof is in the appendix, but the main intuition can be explained as follows. Differently from the previous case, it is not possible to characterize the solution by looking at the first order conditions of the maximization problem. The proof of the theorem involves the following steps. For any policy $(p, T, S)$, define

$$
H(p, T, S)=\int_{\underline{s}}^{\bar{s}} S(s) f(s) d s+\int_{0}^{\infty} e^{-r t}\left(p(t)-p_{I}\right) Q(p(t), t) d t,
$$

i.e. $H(p, T, S)$ is the cost of the subsidies given to firms under that policy. Let $p^{*}, T^{*}, S^{*}$ be piecewise continuous functions that (together with $D^{*}$ and $\left.\tau^{*}\right)$ solve the optimal control problem, and let $H^{*}$ be the cost of the subsidies given to firms under the optimal policy. For each integer number $n$ we consider the following transformed optimization problem: Choose the functions $p, T, S$ in such a way that each function takes at most $n$ distinct values. Let $\left(p^{n}, T^{n}, S^{n}\right)$ be the solution to this modified problem. We show first that 
for each $\epsilon>0$ it is possible to find $n_{\epsilon}$ such that $H\left(p^{n_{\epsilon}}, T^{n_{\epsilon}}, S^{n_{\epsilon}}\right)-H^{*}<\epsilon$ and each firm obtains at least as much as under the optimal policy. This implies that for each $\epsilon$ we can find a policy involving only a finite number of changes in prices, exit times and subsidies and giving at least the same utility to the firms and 'almost' the same utility to the consumers (i.e. the consumers have to finance a subsidy to firms which is only $\epsilon$ higher than the subsidy they pay under the optimal policy).

We next show that $\left(p^{n}, T^{n}, S^{n}\right)=\left(p^{2}, T^{2}, S^{2}\right)$ for each $n$, i.e. the solution to the modified problem is always the same and it involves at most 2 values for each function. We conclude that $H\left(p^{2}, T^{2}, S^{2}\right)-H^{*}<\epsilon$ for each $\epsilon>0$, and therefore $\left(p^{2}, T^{2}, S^{2}\right)$ (together with $D^{*}$ and $\tau^{*}$, which we already know to take at most two values) is a solution of the optimization problem, since each firm is at least as well off as under the optimal program and the cost to consumers is the same.

An analogous result (the optimal policy function is two-stepped) has been obtained by Samuelson [12]. Our result is more general. In his case, the utility function of the informed party is linear in the relevant parameter. This allows him to write the incentive compatibility condition in a much simpler way, and to solve explicitly the maximization problem. In our case, the incentive compatibility condition are more complicated, so that the form of the optimal policy has to be derived through an indirect argument.

\section{Conclusions}

In this paper we have explored the optimal policies that a planner can pursue in order to deregulate an industry when there is incomplete information on the characteristics of the regulated firms and a political constraint of unanimity is imposed. We have shown that, under weak assumptions and provided the planner has commitment power, the optimal policy turns out to be relatively simple, as it involves only a limited number of changes in prices 
and subsidies. Furthermore, deregulation is not complete, as in general it is optimal to allow the survival of some inefficient firms.

\section{Appendix}

\section{Example (from Matt Mitchell)}

The following example is helpful to get a more intuitive sense of the importance of the last part of Assumption 2.

Consider the simple parametric case where $c(q, s)=q^{2} / 2 s$, so that $q(p, s)=p s$. Let $f$ be uniform and begin with $p_{I}=0$. Then the inequality reads:

$$
p \bar{s}-p s \frac{s-\underline{\mathrm{s}}}{\bar{s}-\underline{\mathrm{s}}}-\int_{s}^{\bar{s}} p x \frac{1}{\bar{s}-\underline{\mathrm{S}}} d x<p \int_{s}^{\bar{s}} \frac{x}{\bar{s}-\underline{\mathrm{s}}} d x
$$

or

This holds for $s=\underline{\mathrm{s}}$ iff $\underline{\mathrm{s}}>0$. Since the two sides are equal for $s=\bar{s}$ and the derivative of the LHS with respect to $s$ is everywhere greater than the right, it must hold for all $s$ in the interval.

Now if we reintroduce $p_{I}>0$ the inequality becomes

$$
\bar{s}-s\left(\frac{s-\underline{\mathrm{s}}}{\bar{s}-\underline{\mathrm{s}}}\right)<\frac{\bar{s}^{2}-s^{2}}{\bar{s}-\underline{\mathrm{s}}}-\frac{p_{I}}{2 p} \frac{\bar{s}^{2}-s^{2}}{\bar{s}-\underline{\mathrm{s}}}
$$

At $\underline{s}$ this is just

$$
\bar{s}<(\bar{s}+\underline{\mathrm{s}})\left(1-\frac{p_{I}}{2 p}\right) .
$$

The inequality must hold for $p^{0}>p>p_{I}$, so this is a joint restriction on $p^{0}$ and $\underline{\mathbf{s}}$. The closer $p^{0}$ gets to $p_{I}$, the narrower the range of $s$ must be.

This gives the assumption the following interpretation: the inefficiency is pretty big $\left(p^{0}\right.$ high relative to $\left.p_{I}\right)$ relative to the aymmetric information (the range of $s$.) 
Proof of Proposition 1. Let $U_{0}(v)=\max \left\{0,\left(v-p^{0}\right)\right\} / r$ and $\Pi_{0}(c)=$ $\left(p^{0}-c\right) / r$. The participation constraints are:

$$
U(v) \geq U_{0}(v) \quad \Pi(c) \geq \Pi_{0}(c) .
$$

The incentive compatibility constraints require that:

$$
\tilde{U}(v, v) \geq \tilde{U}\left(v, v^{\prime}\right) \quad \text { for all } v, v^{\prime} \text { in }[0, \bar{v}]
$$

and

$$
\tilde{\Pi}(c, c) \geq \tilde{\Pi}\left(c, c^{\prime}\right) \quad \text { for all } c, c^{\prime} \text { in }\left[0, p^{0}\right] .
$$

Using standard procedures (e.g. Myerson [10]), the incentive compatibility constraints can be replaced by the requirement that $D(v)$ be an increasing function, $A(c)$ decreasing, $U^{\prime}(v)=D(v)$ and $\Pi^{\prime}(c)=-A(c)$ at all points where the functions are differentiable.

The budget constraint (2) can be written as:

$$
\int_{0}^{\bar{v}}\left[D(v)\left(v-p_{I}\right)-U(v)\right] g(v) d v \geq \int_{0}^{p^{0}}\left[\Pi(c)-A(c)\left(p_{I}-c\right)\right] f(c) d c
$$

We can define a common support for the two integrals by setting $f(c)=0$ on $\left(p^{o}, \underline{v}\right]$, so that the budget constraint becomes:

$$
\int_{0}^{\bar{v}}\left\{\left[D(t)\left(t-p_{I}\right)-U(t)\right] g(t)-\left[\Pi(t)-A(t)\left(p_{I}-t\right)\right] f(t)\right\} d t \geq 0,
$$

where $t$ is used as a dummy of integration not to be confused with time. Define the new state variable $y(t)$ as $y(0)=0$ and:

$$
y^{\prime}(t)=\left[D(t)\left(t-p_{I}\right)-U(t)\right] g(t)-\left[\Pi(t)-A(t)\left(p_{I}-t\right)\right] f(t)
$$

Then, the budget constraint is simply given by $y(\bar{v}) \geq 0$. Consider now the following problem:

$$
\max _{D(\cdot), A(\cdot)} \int_{0}^{\bar{v}}(U(t) g(t)+\alpha \Pi(t) f(t)) d t
$$


s.t.

$$
\begin{gathered}
U(t) \geq U_{0}(t) \quad \Pi(t) \geq \Pi_{0}(t) \\
U^{\prime}(t)=D(t) \quad \Pi^{\prime}(t)=-A(t) \\
y^{\prime}(t)=\left[D(t)\left(t-p_{I}\right)-U(t)\right] g(t)-\left[\Pi(t)-A(t)\left(p_{I}-t\right)\right] f(t) \\
\frac{1}{r} \geq D(t) \geq 0 \quad 1 \geq A(t) \geq 0 \quad y(\bar{v}) \geq 0 \quad y(0)=0 .
\end{gathered}
$$

We will propose a solution to this optimal control problem and then show that the sufficient conditions for optimality are satisfied. The proposed optimal control is

$$
\begin{aligned}
& D(t)=0 \text { if } t \leq v^{*}, D(t)=\frac{1}{r} \text { if } t>v^{*} \\
& A(t)=1 \text { if } t \leq c^{*}, A(t)=0 \text { if } t>c^{*}
\end{aligned}
$$

where $\left(c^{*}, v^{*}\right)$ are the solutions to problem (4). Under the optimal control the state variables turn out to be:

$$
\begin{gathered}
U(t)=0 \text { if } t \leq v^{*}, U(t)=\frac{t-v^{*}}{r} \text { if } t>v^{*} \\
\Pi(t)=\frac{p^{o}-t}{r} \text { if } t \leq c^{*}, \Pi(t)=\frac{p^{o}-c^{*}}{r} \text { if } t>c^{*}
\end{gathered}
$$

We now show that the proposed solution satisfies the sufficient conditions of Theorem 5.1 in Seierstad and Sydsæter (see also their Note 5.11). Define the Hamiltonian associated to the problem as

$$
\begin{gathered}
H\left(U, \Pi, D, A, \lambda_{1}, \lambda_{2}, \lambda_{3}, t\right)=U(t) g(t)+\alpha \Pi(t) f(t)+\lambda_{1}(t) D(t)-\lambda_{2}(t) A(t)+ \\
\lambda_{3}(t)\left\{\left[D(t)\left(t-p_{I}\right)-U(t)\right] g(t)-\left[\Pi(t)-A(t)\left(p_{I}-t\right)\right] f(t)\right\} .
\end{gathered}
$$

Since we also have constraints on the state variables, we need to build the Lagrangian $L$ to incorporate them:

$$
\begin{gathered}
L\left(U, \Pi, D, A, \lambda_{1}, \lambda_{2}, \lambda_{3}, \mu_{1}, \mu_{2}, t\right)=H\left(U, \Pi, D, A, \lambda_{1}, \lambda_{2}, \lambda_{3}, t\right)+ \\
\mu_{1}(t)\left[U(t)-U_{0}(t)\right]+\mu_{2}(t)\left[\Pi(t)-\Pi_{0}(t)\right] .
\end{gathered}
$$

A solution to the optimal control problem can be characterized by the array $\left\{U, \Pi, D, A, \lambda_{1}, \lambda_{2}, \lambda_{3}, \mu_{1}, \mu_{2}\right\}$. The solution we propose is: 
- The state variables $U, \Pi$ and the control variables $A, D$ are as previously described (i.e. the solutions to the simplified problem).

- Let $\lambda^{*}$ be the Lagrangian multiplier associated to the budget constraint obtained in the solution of the simplified problem (4). Then we set $\lambda_{3}(t)=\lambda^{*}$ and define the functions $\lambda_{1}, \lambda_{2}$ as:

$$
\lambda_{1}(t)=\left(1-\lambda^{*}\right)(G(\bar{v})-G(t)) \quad \lambda_{2}(t)=\left(\alpha-\lambda^{*}\right)\left(F\left(p^{o}\right)-F(t)\right)
$$

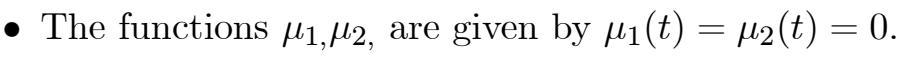

We now go through the laundry list of the conditions.

1. For each $t$, the value of $D(t)$ maximizes $H\left(U, \Pi, D, A, \lambda_{1}, \lambda_{2}, \lambda_{3}, t\right)$ in $t$. This is equivalent to the requirement that the expression $\lambda_{1}(t)+$ $\lambda_{3}(t)\left(t-p_{I}\right) g(t)$ be negative for $t<v^{*}$ and positive otherwise. If we substitute the proposed expression of the lambdas the condition becomes:

$$
\begin{aligned}
& \left(1-\lambda^{*}\right)(G(\bar{v})-G(t))+\lambda^{*}\left(t-p_{I}\right) g(t)>0 \text { if } t>v^{*} \\
& \left(1-\lambda^{*}\right)(G(\bar{v})-G(t))+\lambda^{*}\left(t-p_{I}\right) g(t)<0 \text { if } t<v^{*}
\end{aligned}
$$

The expression $\left(1-\lambda^{*}\right)(G(\bar{v})-G(t))+\lambda^{*}\left(t-p_{I}\right) g(t)$ is identical to the derivative with respect to $v^{*}$ of the Lagrangian in the simplified problem (4). Therefore, it takes value zero at $v^{*}$. Furthermore, given our regularity conditions, the expression is negative for $t<v^{*}$ and positive if $t>v^{*}$. Therefore, the condition is satisfied.

2. For each $t$, the value of $A(t)$ maximizes $H\left(U, \Pi, D, A, \lambda_{1}, \lambda_{2}, \lambda_{3}, t\right)$ in $t$. Using the same reasoning, the condition becomes

$$
\begin{aligned}
& \left(\lambda^{*}-\alpha\right)\left(F\left(p^{o}\right)-F(t)\right)-\lambda^{*}\left(t-p_{I}\right) f(t)>0 \text { if } t<c^{*} \\
& \left(\lambda^{*}-\alpha\right)\left(F\left(p^{o}\right)-F(t)\right)-\lambda^{*}\left(t-p_{I}\right) f(t)<0 \text { if } t>c^{*}
\end{aligned}
$$

Again, by definition of $\lambda^{*}, c^{*}$ the expression is zero at $c^{*}$. The regularity conditions allows us to conclude that the condition is satisfied. 
3. $\lambda_{1}^{\prime}(t)=-\frac{\partial L}{\partial U}, \lambda_{2}^{\prime}(t)=-\frac{\partial L}{\partial \Pi}$ and $\lambda_{1}(\bar{v})=\lambda_{2}(\bar{v})=0$. This follows immediately from the definitions.

4. $\lambda_{3} \geq 0$. This follows from the first order condition of the simplified problem.

5. The function $\widehat{H}\left(U, \Pi, \lambda_{1}, \lambda_{2}, \lambda_{3}, t\right)=\max _{D, A}$ feasible $H\left(U, \Pi, D, A, \lambda_{1}, \lambda_{2}, \lambda_{3}, t\right)$ is concave in $U$ and $\Pi$. This follows immediately from the linearity of $H$.

6. The constraints on the state variables are described by quasi-concave function, i.e. $U-\max \left\{\frac{t-p^{o}}{r}, 0\right\}$ and $\Pi-\frac{p^{o}-t}{r}$ are respectively quasiconcave in $U$ and $\Pi$. Again, this follows from linearity.

This completes the requirements, and we can conclude that the proposed solution is in fact optimal.

Proof of Proposition 2. We show that $W\left(c^{*}, \alpha\right)$ satisfies decreasing differences in $c^{*} ; \alpha$. This implies, by Topkis' theorem (see Topkis [16]), that $c^{*}$ is decreasing in $\alpha$. To show decreasing differences it is enough to show that the second mixed derivative is non positive. By direct computation:

$$
\frac{\partial^{2} W}{\partial \alpha \partial c^{*}}=F\left(c^{*}\right)-F\left(p^{o}\right) \leq 0
$$

We can therefore conclude that $c^{*}$ is decreasing in $\alpha$.

Proof of Lemma 1. Let $\left\{\tau^{*}, D^{*}, p^{*}, T^{*}, S^{*}\right\}$ be an optimal policy. Define the cost of the subsidy program on the firms' side under the optimal policy as:

$$
F^{*}=\int_{\underline{s}}^{\bar{s}} S^{*}(s) f(s) d s+\int_{0}^{\infty} e^{-r t}\left(p^{*}(t)-p_{I}\right) Q^{*}\left(p^{*}(t), t\right) d t
$$

Under the optimal policy the functions $\tau^{*}(v)$ and $D^{*}(v)$ must solve:

$$
\max _{\tau, D} \int_{\underline{v}}^{\bar{v}}\left(D(v)\left(v-p_{I}\right)-\tau(v)\right) g(v) d v
$$


s.t.

$$
U(v) \geq U_{0}(v) \quad U^{\prime}(v)=D(v) \quad \int_{\underline{v}}^{\bar{v}} \tau(v) g(v) d v \geq F^{*}
$$

This program has the same structure as the one solved in section 2, and we can therefore conclude that the optimal way of financing a given transfer to firms is simply to set a constant excise tax $X$ and let consumers buy the good at $p_{I}+X$.

Proof of Proposition 3. Let $H\left(p^{*}, T^{*}, S^{*}\right)$ and $H\left(p^{n}, T^{n}, S^{n}\right)$ be defined as in the discussion after the theorem, and $\Pi(s)$ as the total profit obtained by a firm of type $s$ under the optimal program. We first show that we can find a policy taking a finite number of values and delivering 'almost' the same welfare as the optimal policy.

Lemma 2 For each $\epsilon>0$ there exists $n_{\epsilon}$ such that $H\left(p^{n_{\epsilon}}, T^{n_{\epsilon}}, S^{n_{\epsilon}}\right)-$ $H\left(p^{*}, T^{*}, S^{*}\right)<\epsilon$.

Proof. Under the optimal policy $p^{*}, T^{*}, S^{*}$ the value of the objective function $H^{*}$ is finite, since the total amount that can be extracted from consumers under the individual rationality constraint is finite, so that for each $\delta>0$ it is possible to find a large enough $t^{*}$ such that:

$$
\begin{gathered}
\int_{t^{*}}^{T^{*}(\bar{s})} e^{-r t}\left|\pi\left(p^{*}(t), s\right)\right| d t<\delta \quad \text { for each } s \in[\underline{s}, \bar{s}] \\
\int_{t^{*}}^{T^{*}(\bar{s})} e^{-r t}\left(p^{*}(t)-p_{I}\right) Q\left(p^{*}(t), t\right) d t<\delta
\end{gathered}
$$

Define the transformed exit schedule $\hat{T}(s)=\min \left\{T^{*}(s), t^{*}\right\}$. For any given integer $N$, define $t_{i}$ as $t_{i}=\frac{i}{N} t^{*}$, i.e. $t_{i}$ is obtained as an end point of the partition of $\left[0, t^{*}\right]$ into $N$ intervals of equal length. Define the price schedule $p^{N}$ as:

$$
p^{N}(t)=\left\{\begin{array}{lll}
p\left(t_{i}\right) & \text { if } & t \in\left[t_{i-1}, t_{i}\right) \\
p_{I} & \text { if } & t \geq t^{*}
\end{array}\right.
$$


Next define the exit schedule $\hat{T}^{k}$ as follows. Let $s(1), s(2), \ldots, s(n)$ be points of discontinuity of $\hat{T}$ with jumps greater or equal than $\delta$. Since $\hat{T}$ is bounded, the number of these jumps is finite. Then partition each one of the intervals $[s(i), s(i+1)]$ into $k$ intervals of equal size. Let us call $\left\{\underline{s}, s_{1}, \ldots, s_{z}, \bar{s}\right\}$ the end points of the intervals so obtained, and define the exit schedule $\hat{T}^{k}(s)$ as:

$$
\hat{T}^{k}(s)= \begin{cases}\hat{T}\left(s_{i}\right) & \text { if } \quad s \in\left(s_{i-1}, s_{i}\right] \quad \text { and } \quad i>1 \\ \hat{T}\left(s_{1}\right) & \text { if } \quad s \in\left[\underline{s}, s_{1}\right]\end{cases}
$$

Define now $\hat{Q}^{k}\left(p^{N}(t), t\right)$ as:

$$
\hat{Q}^{k}\left(p^{N}(t), t\right)=\int_{\left(\hat{T}^{k}\right)^{-1}(t)}^{\bar{s}} q\left(p^{N}(t), s\right) d F(s)
$$

that is, $\hat{Q}^{k}\left(p^{N}(t), t\right)$ is the total quantity produced at time $t$ by domestic firms when the exit schedule $\hat{T}^{k}$ and price schedule $p^{N}$ are adopted. The numbers $k$ and $N$ can be chosen so that:

$$
\begin{gathered}
\left|\int_{0}^{t_{\delta}} e^{-r t}\left(p^{*}(t)-p_{I}\right) Q^{*}\left(p^{*}(t), t\right) d t-\int_{0}^{t_{\delta}} e^{-r t}\left(p^{N}(t)-p_{I}\right) Q^{k}\left(p^{N}(t), t\right) d t\right| \leq \delta \\
\quad \int_{T^{*}(s)}^{\hat{T}^{k}\left(s_{i}\right)} \bar{\pi}(p(t)) d t \leq \delta \quad \text { for each } i \quad \text { and } \quad s \in\left(s_{i-1}, s_{i}\right] \\
\int_{T^{*}\left(s_{i}\right)}^{\hat{T}^{k}\left(s_{i+1}\right)} e^{-r t}\left|\pi\left(p(t), s_{i+1}\right)-\pi\left(p^{N}(t), s_{i}\right)\right| d t<r \delta \quad \text { for } \quad \text { each } i \\
\quad \int_{0}^{\hat{T}^{k}\left(s_{i}\right)} e^{-r t}\left|\pi\left(p(t), s_{i}\right)-\pi\left(p^{N}(t), s_{i}\right)\right| d t<r \delta \quad \text { for } \quad \text { each } i
\end{gathered}
$$

The last element to be defined is the transfer function $\widehat{S}$. This is done recursively as follows:

$$
\begin{gathered}
\widehat{S}(\bar{s})=\Pi(\bar{s})-\int_{0}^{\hat{T}^{k}(\bar{s})} e^{r t} \pi\left(p^{N}(t), \bar{s}\right) d t+7 \delta \\
\widehat{S}\left(s_{i}\right)=\int_{\hat{T}^{k}\left(s_{i}\right)}^{\hat{T}^{k}\left(s_{i+1}\right)} e^{-r t} \pi\left(p^{N}(t), s_{i}\right) d t+\widehat{S}\left(s_{i+1}\right)
\end{gathered}
$$


and $\widehat{S}(s)=\widehat{S}\left(s_{i}\right)$ for $s \in\left(s_{i-1}, s_{i}\right]$. Notice that $\widehat{S}$ is constructed to make sure that incentive compatibility is satisfied.

We now show that the subsidy is such that $\widehat{S}(s)<S(s)+12 \delta$ and the profit obtained by a firm of type $s$ is at least $\Pi(s)$. To show that $\widehat{S}(s)<S(s)+12 \delta$ for each $s$, let $\widetilde{S}(s)=\widehat{S}(s)-7 \delta$. We will show that $\mid \widetilde{S}(s)-$ $S(s) \mid<5 \delta$, so that the conclusion immediately follows. To do this, we start from $\bar{s}$. For this case we have:

$$
S(\bar{s})=\Pi(\bar{s})-\int_{0}^{T^{*}(\bar{s})} e^{-r t} \pi(p(t), \bar{s}) d t
$$

Thus:

$$
\begin{gathered}
|\widetilde{S}(\bar{s})-S(\bar{s})|=\left|\int_{\hat{T}^{k}(\bar{s})}^{T^{*}(\bar{s})} e^{-r t} \pi(p(t), \bar{s}) d t+\int_{0}^{\hat{T}^{k}(\bar{s})} e^{-r t}\left[\pi(p(t), \bar{s})-\pi\left(p^{N}(t), \bar{s}\right)\right] d t\right| \leq \\
\int_{\hat{T}^{k}(\bar{s})}^{T^{*}(\bar{s})} e^{-r t}|\pi(p(t), \bar{s})| d t+\int_{0}^{\widehat{T}^{k}(\bar{s})} e^{-r t}\left|\pi(p(t), \bar{s})-\pi\left(p^{N}(t), \bar{s}\right)\right| d t<2 \delta
\end{gathered}
$$

where the last inequality follows from construction of $\hat{T}^{k}$ and $p^{N}$.

Consider now the break points $s_{i}$. The quantity $\widetilde{S}\left(s_{i}\right)$ satisfies the recursive relation:

$$
\widetilde{S}\left(s_{i}\right)=\sum_{j=i}^{k} \int_{\hat{T}^{k}\left(s_{j}\right)}^{\hat{T}^{k}\left(s_{j+1}\right)} e^{-r t} \pi\left(p^{N}(t), s_{j}\right) d t+\widetilde{S}(\bar{s})
$$

Consider now the original transfer and exit schedules, $S$ and $T$. Incentive compatibility requires that for each $i$ :

$$
\int_{T\left(s_{i}\right)}^{T\left(s_{i+1}\right)} e^{-r t} \pi\left(p(t), s_{i}\right) d t \geq S\left(s_{i}\right)-S\left(s_{i+1}\right) \geq \int_{T\left(s_{i}\right)}^{T\left(s_{i+1}\right)} e^{-r t} \pi\left(p(t), s_{i}\right) d t
$$

where the first inequality follows from the fact that type $s_{i+1}$ has no incentive to pretend to be $s_{i}$, and the second follows from a symmetric argument. Repeated substitution yields:

$$
\sum_{j=i}^{k} \int_{T\left(s_{j}\right)}^{T\left(s_{j+1}\right)} e^{-r t} \pi\left(p(t), s_{j+1}\right) d t \geq S\left(s_{i}\right)-S(\bar{s}) \geq \sum_{j=i}^{k} \int_{T\left(s_{j}\right)}^{T\left(s_{j+1}\right)} e^{-r t} \pi\left(p(t), s_{j}\right) d t
$$


Using (11) and the left inequality in (12) we obtain:

$$
\begin{aligned}
S\left(s_{i}\right) & -\widetilde{S}\left(s_{i}\right) \leq \sum_{j=i}^{k} \int_{T\left(s_{j}\right)}^{T\left(s_{j+1}\right)} e^{-r t} \pi\left(p(t), s_{j+1}\right) d t+S(\bar{s}) \\
& -\left[\sum_{j=i}^{k} \int_{\hat{T}^{k}\left(s_{j}\right)}^{\hat{T}^{k}\left(s_{j+1}\right)} e^{-r t} \pi\left(p^{N}(t), s_{j}\right) d t+\widetilde{S}(\bar{s})\right]
\end{aligned}
$$

We will show that the RHS of this expression is less than $4 \delta$.

Let $j^{*}$ be the lowest $j$ such that $T\left(s_{j^{*}}\right) \leq t^{*} \leq T\left(s_{j^{*}+1}\right)$. Then:

$$
\begin{gathered}
\sum_{j=i}^{j^{*}} \int_{\hat{T}^{k}\left(s_{j}\right)}^{\hat{T}^{k}\left(s_{j+1}\right)} e^{-r t}\left(\pi\left(p(t), s_{j+1}\right)-\pi\left(p^{N}(t), s_{j}\right)\right) d t+ \\
\int_{t^{*}}^{T\left(s_{j^{*}+1}\right)} e^{-r t} \pi\left(p(t), s_{j^{*}+1}\right) d t+\sum_{j=j^{*}+1}^{k} \int_{T\left(s_{j}\right)}^{T\left(s_{j+1}\right)} e^{-r t} \pi\left(p(t), s_{j+1}\right)+S(\bar{s})-\widetilde{S}(\bar{s}) \leq \\
\sum_{j=i}^{j^{*}} \int_{\hat{T}^{k}\left(s_{j}\right)}^{\hat{T}^{k}\left(s_{j+1}\right)} e^{-r t}\left|\pi\left(p(t), s_{j+1}\right)-\pi\left(p^{N}(t), s_{j}\right)\right| d t+ \\
\int_{t^{*}}^{T\left(s_{j^{*}+1}\right)} e^{-r t}\left|\pi\left(p(t), s_{j^{*}+1}\right)\right| d t+\sum_{j=j^{*}+1}^{k-1} \int_{T\left(s_{j}\right)}^{T\left(s_{j+1}\right)} e^{-r t}\left|\pi\left(p(t), s_{j+1}\right)\right| d t+|S(\bar{s})-\widetilde{S}(\bar{s})|<4 \delta
\end{gathered}
$$

where the inequality follows from the construction of $\widehat{T}^{k}$ and $p^{N}$. An analogous argument using (11) and the right inequality in (12) yields $S\left(s_{i}\right)-$ $\widetilde{S}\left(s_{i}\right)>-4 \delta$, so that we conclude:

$$
\left|S\left(s_{i}\right)-\widetilde{S}\left(s_{i}\right)\right|<4 \delta
$$

At last, we have to prove $|S(s)-\widetilde{S}(s)|<5 \delta$ for values of $s$ which are not break points. Consider $s \in\left(s_{i-1}, s_{i}\right]$. By incentive compatibility:

$$
-\delta<\int_{T^{*}(s)}^{T^{*}\left(s_{i}\right)} e^{-r t} \pi(p(t), s) d t \leq S\left(s_{i}\right)-S(s) \leq \int_{T^{*}(s)}^{T^{*}\left(s_{i}\right)} e^{-r t} \pi(p(t), s) d t<\delta
$$

so that we conclude $\left|S\left(s_{i}\right)-S(s)\right|<\delta$. Using $\widetilde{S}(s)=\widetilde{S}\left(s_{i}\right)$ we have:

$$
|\widetilde{S}(s)-S(s)|=\left|\widetilde{S}\left(s_{i}\right)-S(s)\right| \leq\left|\widetilde{S}\left(s_{i}\right)-S\left(s_{i}\right)\right|+\left|S\left(s_{i}\right)-S(s)\right|<5 \delta
$$


Last, we have to show that a firm of type $s$ obtains at least $\Pi(s)$. The discounted profit under the discrete scheme for a firm of type $s$ is given by:

$$
\hat{\Pi}(s)=\int_{0}^{\hat{T}^{k}(s)} e^{-r t}\left(\pi\left(p^{N}(t), s\right)\right) d t+\widetilde{S}(s)+7 \delta
$$

Using definitions:

$$
\begin{gathered}
\hat{\Pi}(s)-\Pi(s)=\int_{0}^{\hat{T}^{k}(s)} e^{-r t}\left(\pi\left(p^{N}(t), s\right)-\pi(p(t), s)\right) d t+ \\
-\int_{\hat{T}^{k}(s)}^{T^{*}(s)} e^{-r t}(\pi(p(t), s)) d t+\widetilde{S}(s)-S(s)+7 \delta \geq-\delta-\delta-5 \delta+7 \delta=0
\end{gathered}
$$

so that the conclusion follows.

Consider now the total cost of this policy to the planner.

$$
\begin{gathered}
H^{N}=\int_{\underline{s}}^{\bar{s}} \widehat{S}(s) d F(s)+\int_{0}^{t^{*}} e^{-r t}\left(p^{N}(t)-p_{I}\right) \hat{Q}^{k}\left(p^{N}(t), t\right) d t \leq \\
\int_{\underline{s}}^{\bar{s}} S(s) d F(s)+12 \delta+\int_{0}^{+\infty} e^{-r t}\left(p^{*}(t)-p_{I}\right) Q\left(p^{*}(t), t\right) d t+2 \delta=H^{*}+14 \delta
\end{gathered}
$$

By choosing $\delta=\frac{\epsilon}{14}$ we obtain $H^{N} \leq H^{*}+\epsilon$.

The next move is to prove that discrete policies have two steps. We first prove the following result.

Lemma 3 The function $\pi(p, s)$ is supermodular.

Proof. It is enough to show that $\frac{\partial^{2} \pi}{\partial p \partial s} \geq 0$. By the envelope theorem $\frac{\partial \pi}{\partial p}=q(p, s)$, and by assumption (2), part (2), we have $\frac{\partial q}{\partial s} \geq 0$.

At last we prove the following:

Lemma 4 Let $\left(p^{N}, T^{N}, S^{N}\right)$ be the optimal control when at most $N$ distinct values are allowed. Then for each $N$ there is a solution such that at most two values are taken. 
Proof. Let $\underline{s}=s_{0}, s_{1}, \ldots, s_{N}=\bar{s}$ be a partition of the interval $[\underline{s}, \bar{s}]$, and for each $i=1, \ldots, N$ let $T_{i}$ be the time of exit for firm of type $s \in\left[s_{i-1}, s_{i}\right)$, and set $T_{0}=0$. Since the mechanism makes no distinction between different firms except for the time at which they leave, the transfers will be given by a vector $S_{1}, \ldots, S_{N}$, with $S_{i}$ being the subsidy paid to a firm announcing $s \in\left[s_{i-1}, s_{i}\right)$. For each $i=1, \ldots, N$, let $p_{i}$ denote the price specified by the mechanism between periods $T_{i-1}$ and $T_{i}$. We will consider the optimal choice of $\left\{T_{i}, s_{i}, p_{i}, S_{i}\right\}_{i=}^{N}$, together with a tax $\tau$, for a given $N$, under the individual rationality and incentive compatibility constraints for firms and a balanced budget constraint. Let:

$$
\beta_{i}=\frac{e^{-r T_{i-1}}-e^{-r T_{i}}}{r} \quad i=1, \ldots, N
$$

Note that $\beta_{i}$ is the present value of a unit flow between periods $T_{i-1}$ and $T_{i}$ and $\sum_{i=1}^{N} \beta_{i} \leq \frac{1}{r}$ (with equality if $T_{N}=+\infty$ ). The IR constraint for a firm of type $s$ exiting at time $T_{i}$ is:

$$
\sum_{j=1}^{i} \beta_{j} \pi\left(p_{j}, s\right)+S_{i} \geq \frac{\pi\left(p^{o}, s\right)}{r} \quad i=1, \ldots, N
$$

The IC constraint implies that a firm of type $s_{i}$ is indifferent between leaving at $T_{i}$ or at $T_{i+1}$. Therefore:

$$
S_{i}=\beta_{i+1} \pi\left(p_{i+1}, s_{i}\right)+S_{i+1} . \quad i=1, \ldots, N-1
$$

By repeated substitution of (14) we obtain:

$$
S_{i}=\sum_{j=i+1}^{N} \beta_{j} \pi\left(p_{j}, s_{j-1}\right)+S_{N} \quad i=1, \ldots, N-1
$$

We will solve the problem imposing only incentive compatibility and the condition that a firm of type $\bar{s}$ obtains at least $\frac{\pi\left(p^{o}, \bar{s}\right)}{r}$. We will next show that the solution is feasible, i.e. each firm of type $s$ obtains at least $\frac{\pi\left(p^{o}, s\right)}{r}$. 
Let $Q\left(s_{i-1}, p_{i}\right)=\int_{s_{i-1}}^{\bar{s}} q\left(p_{i}, s\right) d F(s)$ denote the total output flow produced each period $t \in\left[T_{i-1}, T_{i}\right)$ by firms in the industry. The total cost to be financed by taxes is:

$$
C=\sum_{i=1}^{N}\left(F\left(s_{i}\right)-F\left(s_{i-1}\right)\right) S_{i}+\sum_{i=1}^{N} \beta_{i}\left(p_{i}-p_{I}\right) Q\left(s_{i-1}, p_{i}\right)
$$

After rearrangement, and using $F(\bar{s})=1$, we obtain:

$$
\sum_{i=1}^{N}\left(F\left(s_{i}\right)-F\left(s_{i-1}\right)\right) S_{i}=S_{N}+\sum_{i=1}^{N-1} \beta_{i+1} \pi\left(p_{i+1}, s_{i}\right) F\left(s_{i}\right)
$$

so that total cost can be written as:

$$
C=S_{N}+\sum_{i=0}^{N-1} \beta_{i+1}\left(\pi\left(p_{i+1}, s_{i}\right) F\left(s_{i}\right)+\left(p_{i+1}-p_{I}\right) Q\left(p_{i+1}, s_{i}\right)\right)
$$

Consider now total profits. We have:

$$
T P=\sum_{i=1}^{N}\left(F\left(s_{i}\right)-F\left(s_{i-1}\right)\right) S_{i}+\sum_{i=1}^{N}\left[\int_{s_{i-1}}^{s_{i}}\left(\sum_{j=1}^{i} \beta_{j} \pi\left(p_{j}, s\right)\right) f(s) d s\right]
$$

Rearranging terms and using (17) we obtain:

$$
T P=S_{N}+\sum_{i=0}^{N-1} \beta_{i+1}\left(\int_{s_{i}}^{\bar{s}} \pi\left(p_{i+1}, s\right) f(s) d s+\pi\left(p_{i+1}, s_{i}\right) F\left(s_{i}\right)\right)
$$

The relaxed maximization program in which the IR constraint is only imposed for type $\bar{s}$ is:

$$
\max _{\tau, \beta_{i}, s_{i}, p_{i}, S_{N}} \int_{p_{I}+\tau}^{\bar{v}}\left(\frac{v-p_{I}-\tau}{r}\right) g(v) d v+\alpha T P
$$

s.t.

$$
\begin{gathered}
\sum_{i=1}^{N} \beta_{i} \leq \frac{1}{r} \\
\tau\left(G(\bar{v})-G\left(p_{I}+\tau\right)\right) \geq C \\
\sum_{j=1}^{N} \beta_{j} \pi\left(p_{j}, \bar{s}\right)+S_{N} \geq \frac{\pi\left(p^{o}, \bar{s}\right)}{r}
\end{gathered}
$$


Let $\left(\tau^{*}, \beta_{i}^{*}, s_{i}^{*}, p_{i}^{*}, S_{N}^{*}\right)$ be a solution to this problem and define $\operatorname{Tax}^{*}=$ $\tau^{*}\left(G(\bar{v})-G\left(p_{I}+\tau^{*}\right)\right)$ (tax revenue under the optimal policy). It must be the case that the array $\left\{S_{N}^{*}, \beta_{1}^{*}, \ldots, \beta_{N}^{*}, p_{1}^{*}, \ldots, p_{N}^{*}, s_{1}^{*}, \ldots, s_{N-1}^{*}\right\}$ solves the following problem:

$\max _{S_{N},\left\{\beta_{i}\right\}_{i=1}^{N},\left\{p_{i}\right\}_{i=1}^{N},\left\{s_{i}\right\}_{i=1}^{N-1}} S_{N}+\sum_{i=1}^{N} \beta_{i}\left(\int_{s_{i-1}}^{\bar{s}} \pi\left(p_{i}, s\right) f(s) d s+\pi\left(p_{i}, s_{i-1}\right) F\left(s_{i-1}\right)\right)$

s.t.

$$
\begin{gathered}
\sum_{i=1}^{N} \beta_{i} \leq \frac{1}{r} \\
\operatorname{Tax}^{*} \geq S_{N}+\sum_{i=1}^{N} \beta_{i}\left(\pi\left(p_{i}, s_{i-1}\right) F\left(s_{i-1}\right)+\left(p_{i}-p_{I}\right) Q\left(p_{i}, s_{i-1}\right)\right) \\
\sum_{j=1}^{N} \beta_{j} \pi\left(p_{j}, \bar{s}\right)+S_{N} \geq \frac{\pi\left(p^{0}, s\right)}{r} \\
\beta_{i} \geq 0 \quad s_{i} \geq s_{i-1} \quad i=1, \ldots, N
\end{gathered}
$$

where $s_{0}=\underline{s}$ and $s_{N}=\bar{s}$.

The Lagrangian of the problem is:

$$
\begin{aligned}
L= & S_{N}+\sum_{i=1}^{N} \beta_{i}\left(\int_{s_{i-1}}^{\bar{s}} \pi\left(p_{i}, s\right) f(s) d s+\pi\left(p_{i}, s_{i-1}\right) F\left(s_{i-1}\right)\right)-\gamma\left(\sum_{i=1}^{N} \beta_{i}-\frac{1}{r}\right) \\
& -\lambda\left(S_{N}+\sum_{i=1}^{N} \beta_{i}\left(\pi\left(p_{i}, s_{i-1}\right) F\left(s_{i-1}\right)+\left(p_{i}-p_{I}\right) Q\left(p_{i}, s_{i-1}\right)\right)-\operatorname{Tax}^{*}\right) \\
& +\xi\left(\sum_{i=1}^{N} \beta_{i} \pi\left(p_{i}, \bar{s}\right)+S_{N}-\frac{\pi\left(p^{0}, \bar{s}\right)}{r}\right) \\
& +\mu_{1} \beta_{1}+\ldots+\mu_{N} \beta_{N}+\theta_{1}\left(s_{1}-\underline{s}\right)+\ldots+\theta_{N}\left(\bar{s}-s_{N-1}\right)
\end{aligned}
$$

where $\left(\gamma, \lambda, \xi, \mu_{1} \ldots, \mu_{N}, \theta_{1} \ldots, \theta_{N}\right)$ are positive Lagrange multipliers. At the solution the first order conditions must be satisfied. The first order condition for $S_{N}$ implies:

$$
1-\lambda+\xi=0 \text { or } \lambda=1+\xi \geq 1
$$


Next look at the first order condition for $p_{i}, i=1, \ldots, N$. We have:

$$
\begin{gathered}
\beta_{i}\left(\int_{s_{i-1}}^{\bar{s}} \frac{\partial \pi\left(p_{i}, s\right)}{\partial p_{i}} f(s) d s+\frac{\partial \pi\left(p_{i}, s_{i-1}\right)}{\partial p_{i}} F\left(s_{i-1}\right)\right)- \\
-\lambda \beta_{i}\left(\frac{\partial \pi\left(p_{i}, s_{i-1}\right)}{\partial p_{i}} F\left(s_{i-1}\right)+Q\left(p_{i}, s_{i-1}\right)+\left(p_{i}-p_{I}\right) \frac{\partial Q\left(p_{i}, s_{i-1}\right)}{\partial p_{i}}\right)+ \\
+\xi \beta_{i} \frac{\partial \pi\left(p_{i}, \bar{s}\right)}{\partial p_{i}}=0
\end{gathered}
$$

Noticing now that $\frac{\partial \pi(p, s)}{\partial p}=q(p, s)$ and using $\lambda=1+\xi$ we obtain the following ${ }^{11}$ :

$\frac{\xi}{\lambda}\left[q\left(p_{i}, \bar{s}\right)-q\left(p_{i}, s_{i-1}\right) F\left(s_{i-1}\right)-\int_{s_{i-1}}^{\bar{s}} q\left(p_{i}, s\right) f(s) d s\right]=\left(p_{i}-p_{I}\right) \int_{s_{i-1}}^{\bar{s}} \frac{\partial q\left(p_{i}, s\right)}{\partial p} f(s) d s$

Equation (22) implies $p_{i} \leq p^{0}$ for each $i=1, \ldots, N$. It follows from assumption 2, part 3 that the left hand side is always smaller that the right hand side when $p \geq p^{0}$ (remember that $\frac{\xi}{\lambda}<1$ ). The right hand side is always positive, since the supply function is strictly increasing in $s$ for any given $p$. We also notice that a solution to equation (22) exists, since at $p_{i}=0$ the right hand side is negative.

Having established that at the solution $p_{i} \leq p^{0}$ we can show that the individual rationality constraint is satisfied for each firm. First, we know that the IR constraint is satisfied for type $\bar{s}$, that is the following inequality holds:

$$
\sum_{j=1}^{N} \beta_{j} \pi\left(p_{j}, \bar{s}\right)+S_{N} \geq \frac{\pi\left(p^{0}, \bar{s}\right)}{r}
$$

If there is a $s \in\left[s_{i-1}, s_{i}\right)$ for which the individual rationality constraint is not satisfied, we have:

\footnotetext{
${ }^{11}$ The equation is obtained when $\beta_{i}>0$. If $\beta_{i}=0$ then $p_{i}$ is irrelevant.
} 


$$
\sum_{j=1}^{i} \beta_{j} \pi\left(p_{j}, s\right)+\sum_{j=i+1}^{N} \beta_{j} \pi\left(p_{j}, s_{j-1}\right)+S_{N}<\frac{\pi\left(p^{0}, s\right)}{r}
$$

Combining (23) and (24) we obtain:

$$
\begin{gathered}
\sum_{j=1}^{i} \beta_{j}\left(\pi\left(p_{j}, \bar{s}\right)-\pi\left(p_{j}, s\right)\right)+\sum_{j=i+1}^{N} \beta_{j}\left(\pi\left(p_{j}, \bar{s}\right)-\pi\left(p_{j}, s_{j-1}\right)\right)> \\
\frac{1}{r}\left(\pi\left(p^{0}, \bar{s}\right)-\pi\left(p^{0}, s\right)\right)
\end{gathered}
$$

This is impossible, since supermodularity of $\pi$ implies:

$$
\pi\left(p_{j}, \bar{s}\right)-\pi\left(p_{j}, s\right) \leq \pi\left(p^{0}, s\right)-\pi\left(p^{0}, s\right)
$$

whenever $p_{j} \leq p^{0}$. Furthermore $\sum_{j=1}^{N} \beta_{j} \leq \frac{1}{r}$, thus implying that (25) cannot hold.

To prove now that there is a solution in which at most two $\beta_{i}$ 's are different from zero, let $\left(\left\{p_{i}^{*}\right\}_{i=1}^{N},\left\{s_{i}^{*}\right\}_{i=1}^{N-1}\right)$ be part of a solution to problem (19). It is obvious that at the optimal solution the budget constraint must hold with equality, so we can use it to substitute $S_{N}$. Then the optimal $\beta_{i}$ 's must solve:

$$
\begin{aligned}
\max _{\left\{\beta_{i}\right\}_{i=1}^{N}} & \sum_{i=1}^{N} \beta_{i}\left(\int_{s_{i-1}^{*}}^{\bar{s}} \pi\left(p_{i}^{*}, s\right) f(s) d s+\pi\left(p_{i}^{*}, s_{i-1}^{*}\right) F\left(s_{i-1}^{*}\right)\right)+ \\
\operatorname{Tax}^{*}- & \sum_{i=1}^{N} \beta_{i}\left(\pi\left(p_{i}^{*}, s_{i-1}^{*}\right) F\left(s_{i-1}^{*}\right)+\left(p_{i}^{*}-p_{I}\right) Q\left(p_{i}^{*}, s_{i-1}^{*}\right)\right)
\end{aligned}
$$

s.t.

$$
\begin{gathered}
\sum_{j=1}^{N} \beta_{i} \pi\left(p_{i}^{*}, \bar{s}\right)+T a x^{*}-\sum_{i=1}^{N} \beta_{i}\left(\pi\left(p_{i}^{*}, s_{i-1}^{*}\right) F\left(s_{i-1}^{*}\right)+\left(p_{i}^{*}-p_{I}\right) Q\left(p_{i}^{*}, s_{i-1}^{*}\right)\right) \geq \frac{\pi\left(p^{0}, \bar{s}\right)}{r} \\
\sum_{i=1}^{N} \beta_{i} \leq \frac{1}{r} \quad \beta_{i} \geq 0 \quad i=1, \ldots, N
\end{gathered}
$$


This is a standard linear programming problem, and we can now directly apply the fundamental theorem of linear programming (see Luenberger [11]) which tells us that if a solution exists then there is also a solution in which the number of variables taking non zero values is at most equal to the number of constraints, in this case two.

\section{References}

[1] Ausubel, L. and Deneckere R. (1989) 'Reputation in Bargaining and Durable Goods Monopoly', Econometrica, 57: 511-531.

[2] Coase, R. (1972) 'Durability and Monopoly', Journal of Law and Economics , 15: 143-149.

[3] Davidson, C. and S. Matusz (2006) 'Trade Liberalization and Compensation', forthcoming, International Economic Review.

[4] Davidson, C., S. Matusz and D. Nelson (2006) 'Can Compensation Save Free Trade?', mimeo, Michigan State University.

[5] Dewatripont, M. and Roland G. (1992) 'Economic Reform and Dynamic Political Constraints', Review of Economic Studies, 59: 703-730.

[6] Fernandez, R. and Rodrik D. (1989) 'Resistance to Reform: Status Quo Bias in the Presence of Individual-Specific Uncertainty', American Economic Review, 81: 1146-1155.

[7] Gul F., Sonnenschein H. and Wilson R. (1986) 'Foundations of Dynamic Monopoly and the Coase Conjecture', Journal of Economic Theory, 39: 155-190.

[8] Kydland, Finn and E. Prescott (1977) 'Rules Rather than Discretion: The Inconsistency of Optimal Plans', Journal of Political Economy, 85: 473-491. 
[9] Mitchell, M. and A. Moro (2006) 'Persistent Distortionary Policies with Asymmetric Information', American Economic Review, 96: 387-393.

[10] Myerson, R. (1981) 'Optimal Auction Design', Mathematics of Operation Research, 6:58-73.

[11] Luenberger, D. (1984) Linear and Nonlinear Programming, AddisonWesley, Menlo Park, California.

[12] Samuelson, W. (1984) 'Bargaining under Incomplete Information', Econometrica, 52: 995-1005.

[13] Seierstad, A. and K. Sydsæter (1987) Optimal Control Theory with Economic Applications, North Holland, Amsterdam.

[14] Stokey, N. (1979) 'Intertemporal Price Discrimination', Quarterly Journal of Economics, 93: 355-371.

[15] Stokey, N. (1982) 'Rational Expectations and Durable Goods Pricing', Bell Journal of Economics, 12: 112-128.

[16] Topkis, D. (1978) 'Minimizing a Submodular Function on a Lattice', Operations Research, 26: 305 - 321. 